\title{
Analisa Hasil Implementasi Standard Wi-Fi Direct pada Komunikasi Jaringan Ad-Hoc antar Kendaraan di Wilayah Bandung
}

Heriansyah

Program Studi Teknik Elektro Institut Teknologi Sumatera, Lampung Selatan

Jl. Terusan Ryacudu, Way Hui, Jati Agung, Lampung Selatan 35365

heridel.itera.ac.id

Intisari - Penelitian ini akan menyajikan sebuah studi komprehensif tentang kinerja dan perilaku protokol perutean AODV dan DSDV dengan menggunakan standar Wi-fi Direct. Wifi Direct sendiri merupakan standar jaringan nirkabel baru yang memiliki potensi yang cukup unggul karena bisa digunakan sebagai alternatif untuk menggantikan standar DSRC di VANET. Untuk melihat unjuk kerja dari Wi-fi Direct maka akan dilakukan pengujian pada dua skenario perutean yang berbeda. Kedua skenario pengujian ini akan disimulasikan dengan model mobilitas yang sebenarnya yang ada di wilayah Kota Bandung melalui bantuan simulator NS-2 dan SUMO. Berdasarkan hasil simulasi yang didapat, protokol perutean AODV menghasilkan nilai QoS yang lebih optimal dibandingkan protokol perutean DSDV. Secara keseluruhan, unjuk kerja yang dihasilkan oleh standar Wi-fi Direct dan protokol perutean AODV layak dijadikan alternatif pengganti standar DSRC guna menghasilkan biaya implementasi yang lebih murah.

\section{Kata kunci - AODV, DSDV, VANET, DSRC, Wi-Fi Direct, QoS}

Abstract - This research will present a comprehensive study on the performance and behavior of AODV and DSDV routing protocols by using Wi-Fi Direct standard. DSRC is a well-known technology being considered as the most promising wireless standard in VANET. The potential of Wi-Fi Direct technology should be concerned because it can be an alternative to replace DSRC in VANET. Performance of Wi-fi Direct will be tested in two different routing scenarios. They will be simulated with a realistic mobility model in Bandung City to analyze the performance by using simulator NS-2 and SUMO. Based on simulation results, AODV routing protocol produces better QoS than DSDV routing protocol for Wi-fi Direct . Overall, the performance generated by the Wi-fi Direct standard and the AODV routing protocol deserve alternative to the DSRC standard in order to realize cheaper implementation costs.

Keywords - AODV, DSDV, VANET, DSRC, Wi-Fi Direct, QoS

\section{PENDAHULUAN}

Kemajuan teknologi komunikasi berbasis nirkabel telah minimbulkan harapan diciptakannya berbagai sistem baru yang dapat memberikan kemudahan dalam berbagai aktivitas manusia, salah satunya adalah harapan agar terciptanya sistem transportasi cerdas. Teknologi Vehicular Adhoc Network (VANET) hadir untuk ambil bagian dalam mewujudkan harapan ini.
VANET merupakan jaringan ad-hoc berbasis nirkabel yang terdiri dari kendaraan dan Road Side Unit (RSU). Setiap kendaraan yang berada dalam jangkauan jaringan dapat bertukar informasi melalui metode komunikasi antar kendaraan atau vehicle-tovehicle (V2V) dan komunikasi kendaraan dengan infrastruktur jaringan atau vehicle-toinfrastructure (V2I). Isi pesan tersebut bisa berupa informasi kemacetan, kecelakaan yang menyebabkan jalan tidak dapat diakses, 
informasi mengenai lalu lintas pada rute-rute tertentu ataupun pesan lainnya.

Dalam perkembangannya, berbagai penelitian telah dilakukan untuk meningkatkan kemampuan teknologi ini termasuk pengembangan standar, protokol perutean, aplikasi dan berbagai layanan lainnya. Penelitian ini akan ambil bagian dalam mensimulasikan standar wi-fi yang dapat diterapakan pada teknologi VANET yaitu standar Wi-fi Direct dengan menggunakan protokol perutean DSDV dan AODV. Standar dan protokol perutean ini akan diuji pada dua skenario yang berbeda untuk melihat unjuk kerja dari masingmasing protokol perutean tersebut.

Wi-fi Direct sendiri merupakan standar jaringan nirkabel baru yang memiliki potensi yang cukup unggul karena bisa digunakan sebagai alternatif untuk menggantikan standar DSRC. DSRC sendiri merupakan teknologi terkenal yang dianggap sebagai standar nirkabel yang paling menjanjikan di VANET. Sebaliknya, sebagai standar jaringan nirkabel terbaru, potensi dari Wi-Fi Direct juga perlu dipertimbangkan karena standar ini bisa menjadi alternatif untuk menggantikan teknologi DSRC guna menghasilkan biaya yang lebih rendah dalam implementasinya [1].

Parameter-parameter yang akan dihitung untuk menunjukkan kualitas layanan atau Quality of Service (QoS) pada simulasi ini antara lain throughput, delay, packet delivery ratio (PDR) dan packet loss ratio (PLR). Hasil perhitungan beberapa parameter QoS pada penelitian ini diharapkan dapat menjadi masukkan dalam penerapan dan pengembangan teknologi VANET ke depannya.

\section{VEHICULAR AD-HOC NETWORK (VANET)}

VANET merupakan jaringan ad-hoc berbasis nirkabel yang terdiri dari kendaraan-kendaraan dan RSU. VANET sendiri merupakan bagian dari teknologi MANET, di mana nodal-nodal yang ada pada VANET diwakili oleh kendaraan [2]. Sama halnya dengan MANET, nodal-nodal yang ada pada VANET dapat bergerak bebas dan

Volume 12, No. 1, Januari 2018 tetap dapat terhubung dengan nodal lain di area jangkauan yang telah ditetapkan. VANET sendiri merupakan jaringan yang bersifat self-organized, artinya jaringan nya tidak bergantung pada infrastruktur jaringan yang ada. Tujuan utama dari diciptakannya teknologi ini adalah untuk meningkatkan keselamatan dan kenyamanan pengendara selama berkendara di jalan raya.

Setiap kendaraan yang berada dalam jangkauan jaringan dapat bertukar informasi melalui metode komunikasi antar kendaraan atau V2V dan komunikasi kendaraan dengan infrastruktur jaringan komunikasi atau V2I seperti yang ditunjukkan oleh gambar 1 . Dengan komunikasi ini pengendara dapat mengirimkan dan menerima pesan satu sama

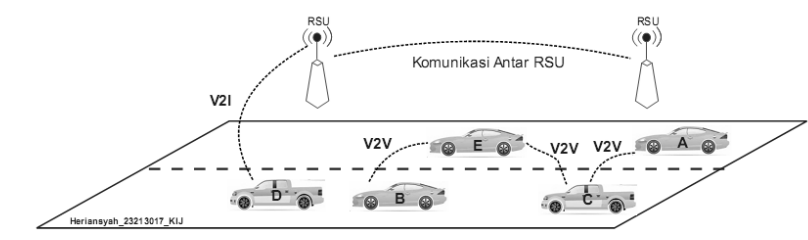

lain.

Gbr. 1 Struktur Komunikasi pada VANET

Dalam penerapannya, VANET memiliki beberapa karakteristik khusus, karakteristik tersebut antara lain [3]:

- Topologi yang sangat dinamis

- Koneksi jaringan yang sering terputus

- Toleransi yang kecil terhadap delay

- Bergantung pada kondisi lingkungan komunikasi

- Bergantung pada informasi yang didapat dari sensor on board

\section{A. Protokol Perutean}

Protokol routing pada VANET dikelompokkan menjadi lima kategori yaitu Topology based, Position based, Cluster based, Geo-Cast based dan Braodcast [4]. Berdasarkan topologinya, protokol ini dibagi menjadi dua kategori lagi yaitu proaktif dan reaktif. Protokol perutean proaktif akan membuat tabel perutean yang berisi tentang hop mana yang akan dilalui untuk mencapai tujuan. Contoh protokol perutean proaktif antara lain DSDV dan FSR [5]. Sedangkan protokol perutean reaktif akan mencari jalur perutean ketika dibutuhkan saja atau sering disebut sebagai on-demand routing protocol. 
Contoh protokol perutean reaktif antara lain AODV dan DSR [7]. Pada penelitian ini, routing protokol proaktif yang akan digunakan adalah DSDV sedangkan AODV digunakan untuk mewakili protokol perutean reaktif.

Destination Sequence Distance Vector (DSDV) merupakan protokol perutean proaktif yang berkerja berdasarkan tabledriven routing protocol untuk berkomunikasi antar perangkat bergerak. Protokol perutean ini menggunakan perhitungan hop dalam pemiliharan rutenya dan dilakukan secara periodik sedangkan Ad hoc On Demand Distance Vector (AODV) protokol AODV hanya akan melakukan pencarian rute ketika ada permintaan saja atau ketika tidak ditemukkan rute untuk mengirimkan suatu paket dari sumber ke tujuannya. Jika rute yang dibutuhkan sudah ada dan dapat digunakan maka fungsi protokol AODV tidak dijalankan sehingga dapat mengurangi beban jaringan.

\section{B. Wi-fi Direct}

Wi-fi Direct merupakan sebuah standar yang didefiniskan oleh Wi-fi Alliance. Dengan standar ini, perangkat wi-fi dapat berkomunikasi secara peer to peer dengan perangkat wi-fi lainnya tanpa menggunakan access point (AP). Perangkat Wi-fi Direct beroperasi pada frekuensi 2,4 Ghz dan bisa terhubung ke standar $802.11 \mathrm{~g}$ dan sebagai 802.11n [11]. Sebagai tambahan, beberapa Wi-fi Direct beroperasi pada frekuensi $5 \mathrm{Ghz}$ untuk mengakomodir standar 802.11a dan beberapa standar $802.11 \mathrm{n}$. Pada Wi-fi Direct, setiap nodal dapat bertindak sebagai AP. Nodal yang menjadi AP disebut sebagai group owner (GO). Setiap client bisa berkomunikasi satu sama lain melalui GO. GO memiliki peran dalam pengambilan keputusan seperti perangkat mana yang bisa bergabung ke dalam grup, kapan grup dimulai dan kapan grup dapat diakhiri.

\section{PERANCANGAN DAN IMPLEMENTASI}

Perancangan dan simulasi pada penelitian ini dibagi ke dalam beberapa tahap dengan menggunakan beberapa perangkat lunak seperti JOSM (Java OpenstreetMap) Editor, Simulator of Urban Mobility (SUMO), Mobility Model Generator for VANET (MOVE), dan Network Simulator versi 2.35 (ns-allinone-2.35) yang digunakan untuk menganalisa unjuk kerja dari scenario yang telah dibuat. Adapun tahap-tahap perancangan dan implementasi simulasi di atas ditunjukkan oleh gambar 2 di bawah ini:

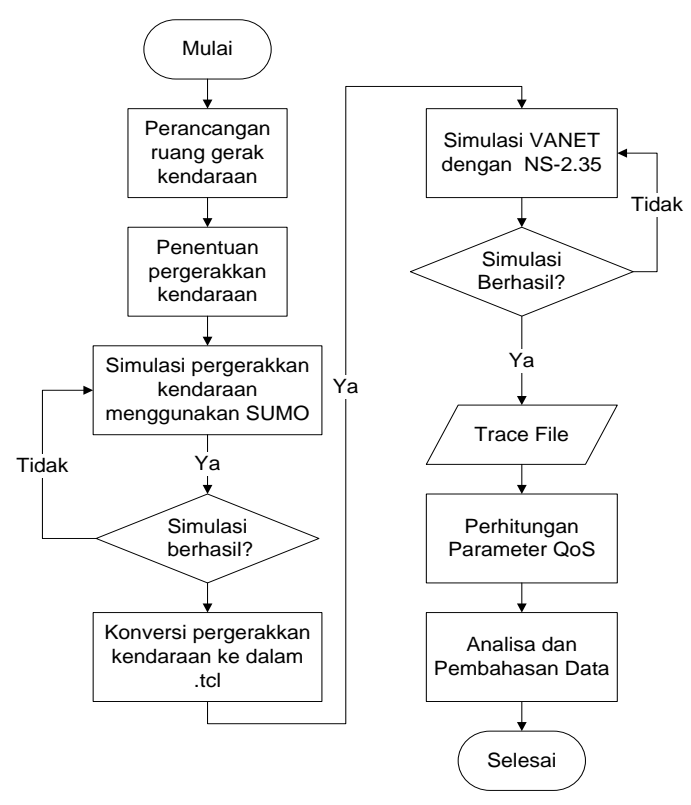

Gbr 2. Bagan alir perancangan simulasi

\section{A. Perancangan Ruang Gerak Kendaraan}

Jalur yang digunakan sebagai ruang gerak kendaraan adalah sebagain jalan yang ada di kota Bandung seperti jalan Asia Afrika, Jalan Sunda, Jalan Tamblong, Jalan Sumatera, Jalam Belitung, Lembong seperti yang ditunjukkan oleh gambar 3 .

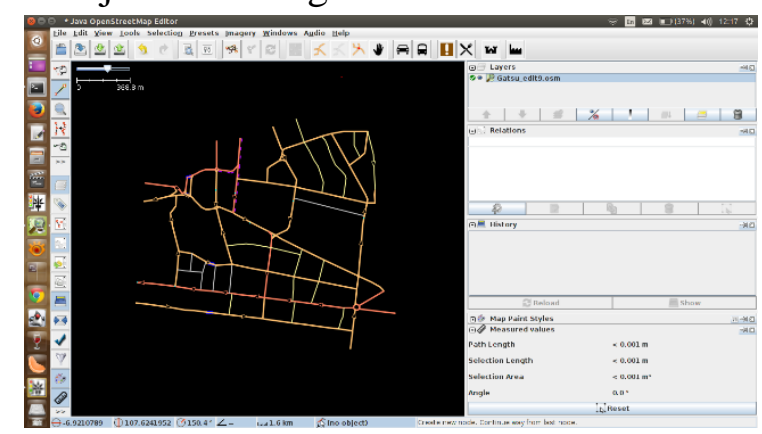

Gbr 3. Peta ruang gerak kendaraan 


\section{B. Perancangan Pergerakkan Kendaraan}

Skenario pergerakkan kendaraan yang disumulasikan pada tahap ini adalah skenario dengan 50, 100, 150, 200, 250 dan 300 kendaraan. Pergerakkan kendaraan pada skenario " $n$ " akan digunakan pada skenario " $n+1$ ". Artinya, simulasi dengan skenario pergerakkan 50 kendaraan tetap akan menggunakan skenario pergerakkan 50 kendaraan sebelumnya ditambah dengan 50 pergerakkan kendaraan yang baru dan begitu seterusnya. Gambar pergerakkan kendaran yang ada pada tampilan grafis sumo ditunjukkan oleh Gbr 4.

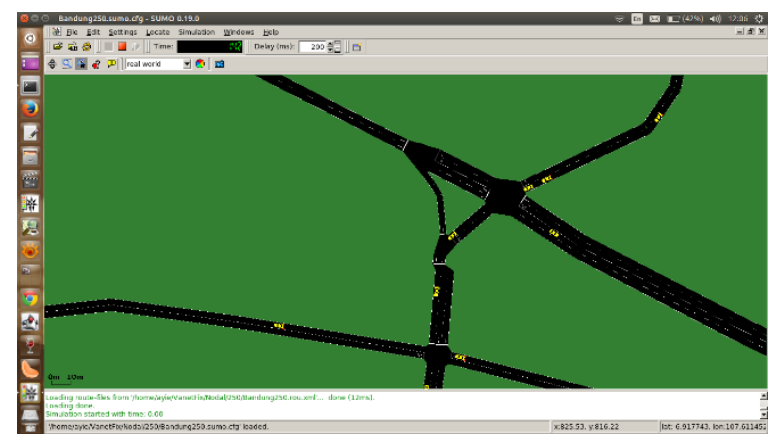

Gbr. 4 Tampilan grafis pergerakkan kendaraan

\section{Parameter Konfigurasi Standar Wi-fi Direct}

Simulasi ini akan dijalankan dengan menggunakan protokol perutean DSDV dan AODV dengan parameter sebagai berikut:

Tabel 1. Parameter Simulasi Kedua

\begin{tabular}{|l|l|}
\hline \multicolumn{1}{|c|}{ Parameter } & \multicolumn{1}{c|}{ Keterangan } \\
\hline Standard & Wi-fi Direct \\
\hline Frekuensi & 2,4 Ghz [10] \\
\hline Data rate & $\begin{array}{l}\text { Up to 250 Mbps } \\
\text { ran] }\end{array}$ \\
\hline Jarak jangkau $[1]$ \\
\hline Protokol perutean & DSDV/AODV \\
\hline Protokol transport & TCP \\
\hline Tipe trafik & CBR \\
\hline Ukuran paket & 512 byte \\
\hline Model propagasi radio & Two ray ground \\
\hline Kecepatan kendaraan & Acak \\
\hline Jumlah kendaraan & $\begin{array}{l}50,100,150,200, \\
250,300\end{array}$ \\
\hline Ukuran ruang gerak & $1500 \mathrm{mx2000} \mathrm{m}$ \\
\hline
\end{tabular}

Volume 12, No. 1, Januari 2018

\section{ANALISIS}

Pada bagian ini akan dilakukan analisis unjuk kerja standar Wi-fi Direct dengan menggunakan protokol AODV dan DSDV. Dua protokol perutean tersebut akan diuji dengan perubahan jumlah kendaraan yang berpartisipasi di dalam ruang gerak simulasi yang telah ditentukan. Adapun kecepatan dari masing-masing kendaraan ditentukan secara acak. Pada skenario ini metrik QoS yang akan dianalisa antara lain throughput, delay, Packet Loss Ratio (PLR) dan Packet Delivery Ratio (PDR). Nilai throughput pada gambar 5 menunjukkan penurunan seiring bertambahnya jumlah kendaraan yang berpartisipasi di dalam ruang gerak simulasi. Hal ini terjadi karena semakin banyak kendaraan yang berpartisipasi dalam ruang gerak simulasi maka semakin cepat topologi jaringan berubah. Topologi dinamis yang dimiliki oleh VANET sendiri dapat menyebabkan penurunan nilai throughput [8]. Selain itu, perubahan topologi jaringan yang sangat cepat dapat menurunkan efisiensi kerja dari protokol perutean seperti protokol AODV yang harus seringkali mencari rute ketika ada permintaan perutean atau protokol DSDV yang harus memutakhirkan tabel peruteannya ketika ada perubahan informasi rute. Ketidak efisienan kerja dari masingmasing protokol ini juga menjadi penyebab turunnya nilai throughput. Pada grafik tersebut dapat kita lihat unjuk kerja protokol perutean AODV menghasilkan unjuk kerja yang lebih baik dibandingkan DSDV.

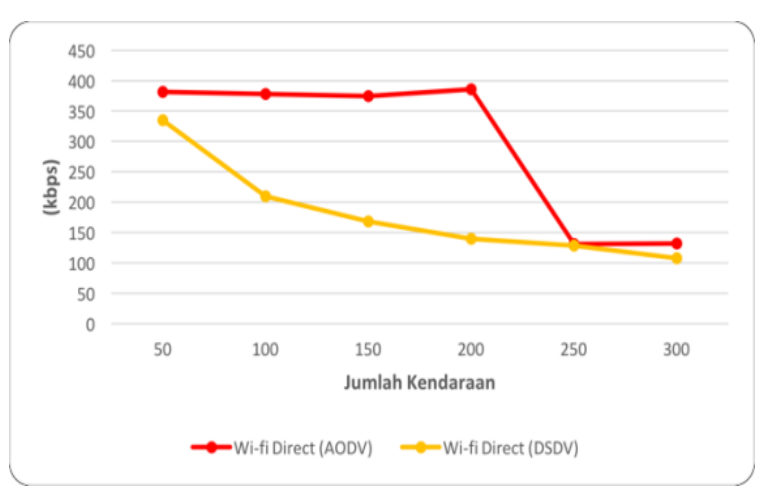

Gbr 5. Grafik Throughput Standar Wi-fi Direct dengan menggunakan AODV dan DSDV 
Grafik perbandingan nilai delay yang dihasilkan ditunjukkan oleh gambar 6. Dari gambar tersebut dapat kita lihat bahwa nilai delay yang dihasilkan menunjukkan peningkatan. Peningkatan ini disebabkan oleh perubahan topologi jaringan yang sangat cepat. Perubahan topologi sendiri akan menyebabkan waktu tempuh pengiriman data dari sumber ke tujuan meningkat. Selain itu, bertambahnya jumlah kendaraan juga mengakibatkan bertambahnya jumlah komunikasi di dalam jaringan. Semakin banyak komunikasi di dalam jaringan maka semakin tinggi kemungkinan terjadinya collision. Untuk menghindari terjadinya collision, maka dibutuhkan waktu backoff. Waktu backoff sendiri merupakan slot waktu yang baru yang digunakan untuk menentukan nodal mana yang bisa lebih dulu mengirimkan data ke nodal tujuan yang sama. Jika terjadi banyak collision di dalam jaringan maka dibutuhkan beberapa kali waktu backoff yang pada akhirnya bisa mengakibatkan peningkatan nilai delay. Delay yang dihasilkan oleh protokol perutean AODV lebih baik dibandingkan DSDV. Namun Nilai delay yang dihasilkan oleh keduanya memenuhi persyaratan minimum delay yang ditetapkan oleh VANET untuk kategori aplikasi traffic efficiency dan value-added services yaitu tidak melebihi $500 \mathrm{~ms}$ [9].

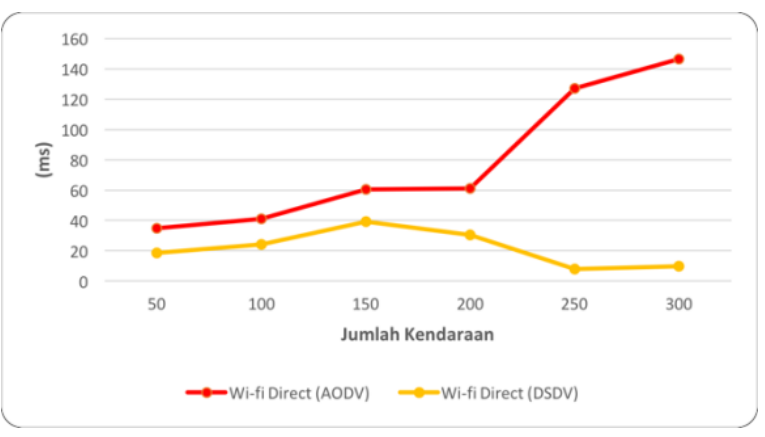

Gbr 6. Grafik Delay Standar Wi-fi Direct dengan menggunakan AODV dan DSDV

Selanjutnya, untuk nilai PLR yang dihasilkan, protokol perutean AODV menghasilkan nilai PLR yang lebih baik dibandingakan protokol perutean DSDV seperti yang ditunjukkan oleh gambar 7. Hal ini disebabkan oleh karakteristik protokol perutean AODV yang hanya akan melakukan pencarian rute ketika ada permintaan saja atau ketika tidak ditemukkan rute untuk Volume 12, No. 1, Januari 2018 mengirimkan suatu paket dari sumber ke tujuannya. Jika rute yang dibutuhkan sudah ada dan dapat digunakan maka fungsi protokol AODV tidak dijalankan sehingga dapat mengurangi beban jaringan. Berbeda dengan AODV, protokol perutean DSDV akan selalu memutakhirkan informasi tabel peruteannya setiap ada perubahan informasi rute. Hal ini dapat menyebabkan beban jaringan bertambah seiring cepatnya perubahan topologi jaringan. Semakin kecil beban jaringan maka semakin kecil pula nilai packet loss yang didapat.

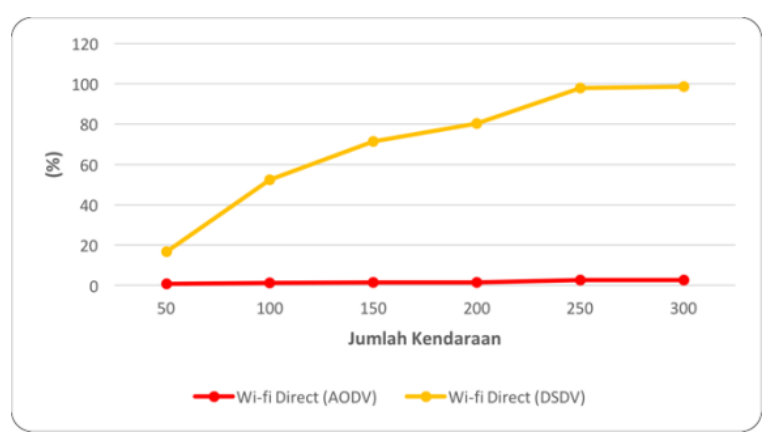

Gbr 7. Grafik PLR Standar Wi-fi Direct dengan menggunakan AODV dan DSDV

Adapun nilai PDR yang dihasilkan oleh kedua protokol perutean tersebut sangat bergantung dengan nilai PLR. Nilai PDR selalu berbanding terbalik dengan nilai PLR, di mana semakin kecil nilai PLR maka semakin besar nilai PDR yang didapat. Berdasarkan gambar 8 maka nilai PDR protokol perutean AODV lebih baik dibandingan protokol perutean DSDV

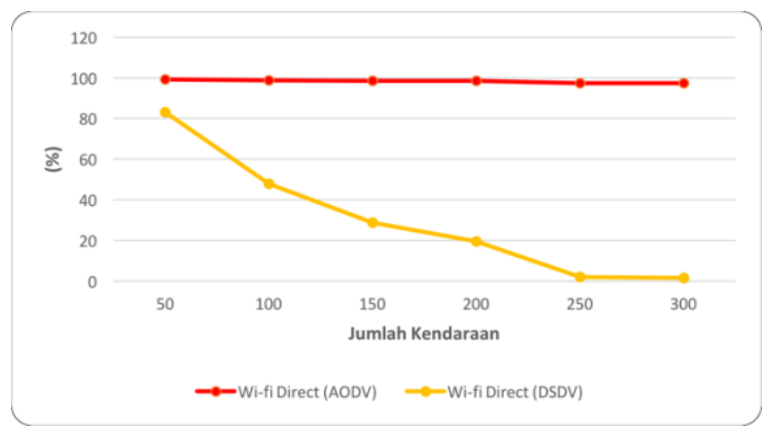

Gbr 8. Grafik PDR Standar Wi-fi Direct dengan menggunakan AODV dan DSDV

\section{KESIMPULAN}

Berdasarkan nilai throughput, delay, PLR dan PDR yang didapat, kombinasi standar Wi-fi Direct dan protokol perutean AODV dapat digunakan sebagai alternatif pengganti 
standar DSRC guna menghasilkan biaya

implementasi yang lebih murah.

\section{REFERENSI}

[1] S. M. Metev and V. P. Veiko, Laser Assisted Microtechnology, 2nd ed., R. M. Osgood, Jr., Ed. Berlin, Germany: Springer-Verlag, 1998.

[2] J. Breckling, Ed., The Analysis of Directional Time Series: Applications to Wind Speed and Direction, ser. Lecture Notes in Statistics. Berlin, Germany: Springer, 1989, vol. 61.

[3] S. Zhang, C. Zhu, J. K. O. Sin, and P. K. T. Mok, "A novel ultrathin elevated channel low-temperature poly-Si TFT," IEEE Electron Device Lett., vol. 20, pp. 569-571, Nov. 1999.

[4] M. Wegmuller, J. P. von der Weid, P. Oberson, and N. Gisin, "High resolution fiber distributed measurements with coherent OFDR," in Proc. ECOC'00, 2000, paper 11.3.4, p. 109.

[5] R. E. Sorace, V. S. Reinhardt, and S. A. Vaughn, "High-speed digital-to-RF converter," U.S. Patent 5668 842, Sept. 16, 1997.

[6] (2002) The IEEE website. [Online]. Available: http://www.ieee.org/

[7] M. Shell. (2002) IEEEtran homepage on CTAN. [Online]. Available: http://www.ctan.org/tex-

archive/macros/latex/contrib/supported/I EEEtran/

[8] FLEXChip Signal Processor (MC68175/D), Motorola, 1996.

[9] "PDCA12-70 data sheet," Opto Speed SA, Mezzovico, Switzerland.

[10]A. Karnik, "Performance of TCP congestion control with rate feedback: TCP/ABR and rate adaptive TCP/IP," $M$. Eng. thesis, Indian Institute of Science, Bangalore, India, Jan. 1999.

[11] J. Padhye, V. Firoiu, and D. Towsley, "A stochastic model of TCP Reno congestion avoidance and control," Univ. of Massachusetts, Amherst, MA, CMPSCI Tech. Rep. 99-02, 1999.

[12] Wireless LAN Medium Access Control (MAC) and Physical Layer (PHY) Specification, IEEE Std. 802.11, 1997. 